\title{
Farmer's Evaluation of a Rolling Canvas Prototype against his own System for Harvesting Olives
}

\author{
A. Almeida ${ }^{(1)}$, J. Peça ${ }^{(2)}$, A. Pinheiro ${ }^{(2)}$, A. Dias ${ }^{(2)}$, L. Santos ${ }^{(3)}$, J. Lopes ${ }^{(4)}$, J. Gomes ${ }^{(4)}$ \\ and D. Reynolds ${ }^{(5)}$
}

(1) Escola Superior Agrária de Bragança, Bragança, Portugal - acfa@ibp.pt

(2) Universidade de Évora, Évora, Portugal

(3) Departamento de Olivicultura da E.N.F.V.N., Elvas, Portugal

(4) Direcção Regional de Agricultura de Trás-os-Montes, Mirandela, Portugal

(5) R\&O, Monte da Granja, Estremoz, Portugal

Keywords: olives / mechanical harvesting / \pm 400 trees/ha.

\begin{abstract}
An olive grower was invited to organise a full day harvesting test based on two rolling canvas prototypes, using his own trunk shaker, tractors and labour. This paper reports the results observed, making also a comparison with the usual harvesting method followed by the farmer, based on a trunk shaker and canvas manually placed under the trees.

Results show that the rolling canvas based system has got a slightly higher work rate, and according to the workers, is less demanding in terms of physical effort.
\end{abstract}

\section{INTRODUCTION}

In order to make a better use of sun light and energy, new plantations of olive orchards in Portugal have a higher number of trees per hectare than the traditional olive orchards.

Almeida et al (2003) revealed the potential of the inverted umbrella linked to the trunk shaker, as the most cost effective harvesting system for the traditional olive orchards.

However, towards densities of approximately 300 or 400 trees per hectare, which means 3.5 to 5 metres between plants in the row, there is not enough space to open the inverted umbrella.

Peça et al (2004) presented a mechanical rolling canvas interceptor prototype designed to be an alternative harvesting system for denser olive orchards (Fig. 1).

The prototype performance was analysed in field tests (Peça et al, 2004), where it was concluded that the equipment should be subjected to an independent trial by the olive grower and his workers.

In this paper are reported the results observed in a full day harvesting test based on two rolling canvas prototypes, using farmer's own trunk shaker, tractors and labour. Results are also compared with the usual harvesting method followed by the farmer.

\section{MATERIALS AND METHODS}

\section{Olive orchards}


Field tests took place in Alentejo region (Portugal), in an olive orchard of cultivar Cobrançosa, planted in a $7 \mathrm{~m} \times 3,5 \mathrm{~m}$ array.

The average yield per tree was $20 \mathrm{~kg}$.

\section{Harvesting systems}

System 1 is the usual farmer harvesting system (Fig. 2): a $75 \mathrm{~kW}$ tractor with a front mounted multidirectional tree shaker follows along the tree lines, harvesting olives onto canvas placed under the trees by six workers who also move the canvas from one tree to the next. When the load on the canvas is too heavy the fruits are transferred to a small storage canvas witch is left behind. Later a tractor with a rear mounted hydraulic crane and a farm trailer is used to load the olives (Fig.4).

System 2 is the alternative harvesting system based on two rolling canvas prototypes, each one moving along its own line of trees. Between the two rows, the same tractor/shaker unit as in System 1 is used to harvest alternatively from each row. Four of the workers of System 1 (two per prototype), are employed to unroll the canvas, as well as to assist at the discharge of the olives when full storage capacity is attained (Fig.3). In System 2 the same equipment and method of System 1 is used to load the olives into a farm trailer.

\section{RESULTS}

With the usual farmer harvesting system (System 1), 91 olive trees were harvested over the period of the trial. The average performance results are presented on Table 1 and 2.

With the alternative harvesting system (System 2), 209 olive trees were harvested over the period of the trial. The average performance results are presented in Table 3 and 4.

\section{DISCUSSION}

Similar results were obtained by the two systems, with a slight advantage to System 2 witch is able to harvest an extra $358 \mathrm{~kg}$ of olives over a full 7 hours work day.

Without any reduction in labour and with two more tractors and two prototypes, costs are a major issue in System 2. However, and according to the workers, System 2 is less demanding on physical effort, something that is extremely relevant when contracting labour in an increasingly difficult market.

\section{ACKNOWLEDGMENTS}

The authors wish to thank the olives growers for their collaboration and the research programme AGRO 271 for the financial support.

\section{Literature Cited}

Almeida, A., Peça, J.O., Pinheiro, A.C., Dias, A.B., Santos, L.S., Reynolds, D., Lopes, J. 2003. Estudo Comparativo do Desempenho de Três Sistemas de Colheita Mecânica de Azeitona. Proceedings of III Simpósio Nacional de Olivicultura. Castelo Branco, Portugal 29-31 Outubro 2003.

Peça, J.O., Almeida, A., Pinheiro, A.C., Dias, A.B., Santos, L.S., Lopes, J., Gomes, J., Reynolds, D. 2004. Mechanical harvesting of 400 trees per hectare olive orchards 
based on a rolling canvas prototype. Presented to the $5^{\text {th }}$ International Symposium on Olive Growing. Izmir, Turkiye 27 September - 2 October 2004.

\section{$\underline{\text { Tables }}$}

Table 1. Performance of farmer's harvesting system (System 1).

\begin{tabular}{cc}
\hline Measurements & Average time (seconds) \\
\hline T1 & 6,9 \\
T2 & 30,8 \\
T3 & 28,5 \\
T4 & 67,7 \\
\hline
\end{tabular}

T1 - average vibrating time per tree; T2 - average time between vibrating two consecutive trees; T3 - average time of actual manoeuvre of the tractor/shaker between two consecutive trees; T4 - average time of discharge.

Table 2. Work rates obtained with farmer's harvesting system (System 1)

\begin{tabular}{cc}
\hline Trees per hour & Trees / man $\mathrm{x}$ hour \\
\hline 77,4 & 11,1 \\
\hline
\end{tabular}

Table 3. Results obtained with alternative harvesting system (System 2).

\begin{tabular}{cc}
\hline Measurements & Average time (seconds) \\
\hline T1 & 7,3 \\
T2 & 32,4 \\
T3 & 30,3 \\
T4 & 234,5 \\
\hline
\end{tabular}

T1 - average vibrating time per tree; T2 - average time between vibrating two consecutive trees; T3 - average time of actual manoeuvre/shaker between two consecutive trees; T4 - average time of discharge.

Table 4 Work rates obtained with alternative harvesting system (System 2)

\begin{tabular}{cc}
\hline Trees per hour & Trees / man $\mathrm{x}$ hour \\
\hline 79,8 & 11,4 \\
\hline
\end{tabular}

\section{Figures}




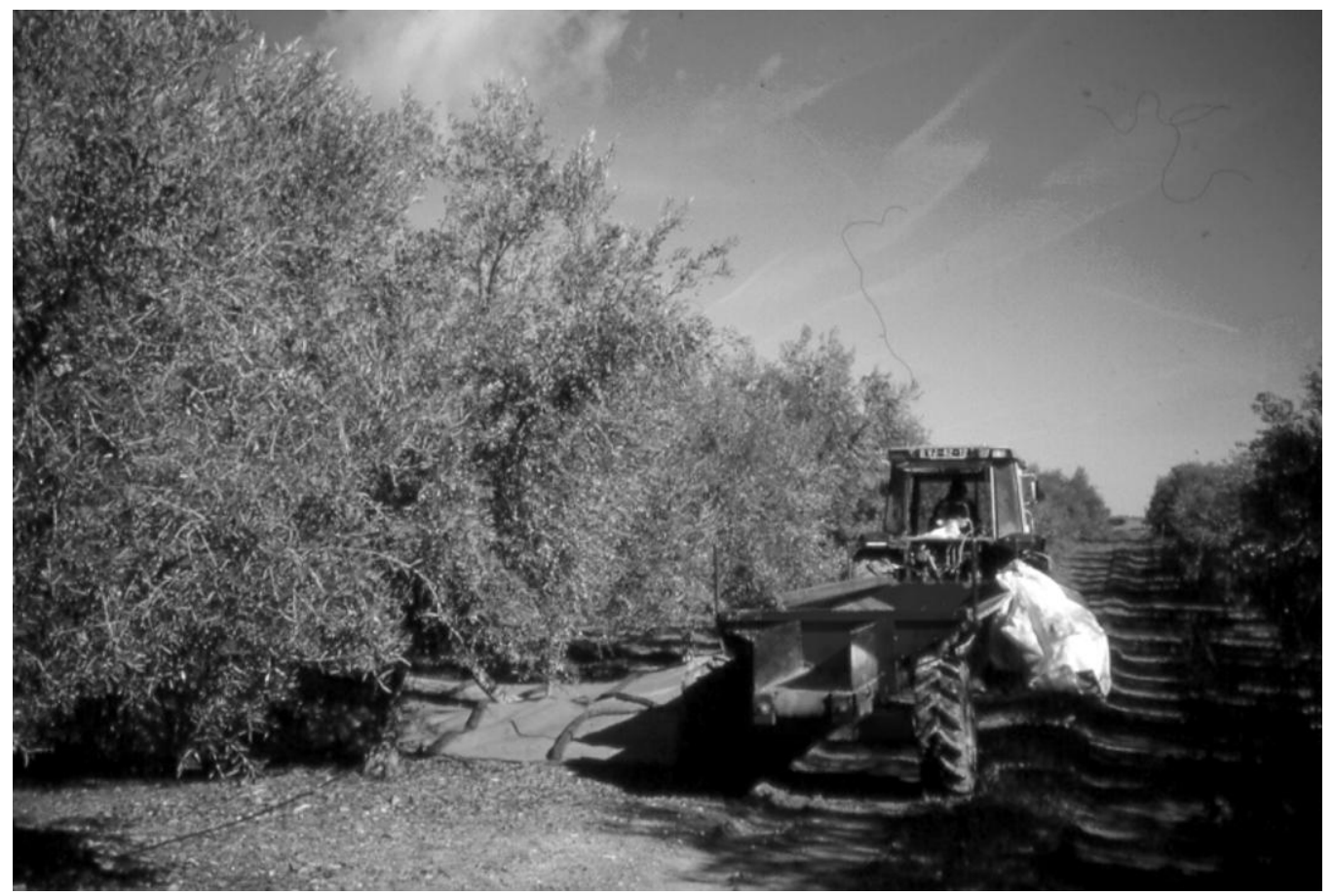

Fig.1. Rolling canvas prototype at work.

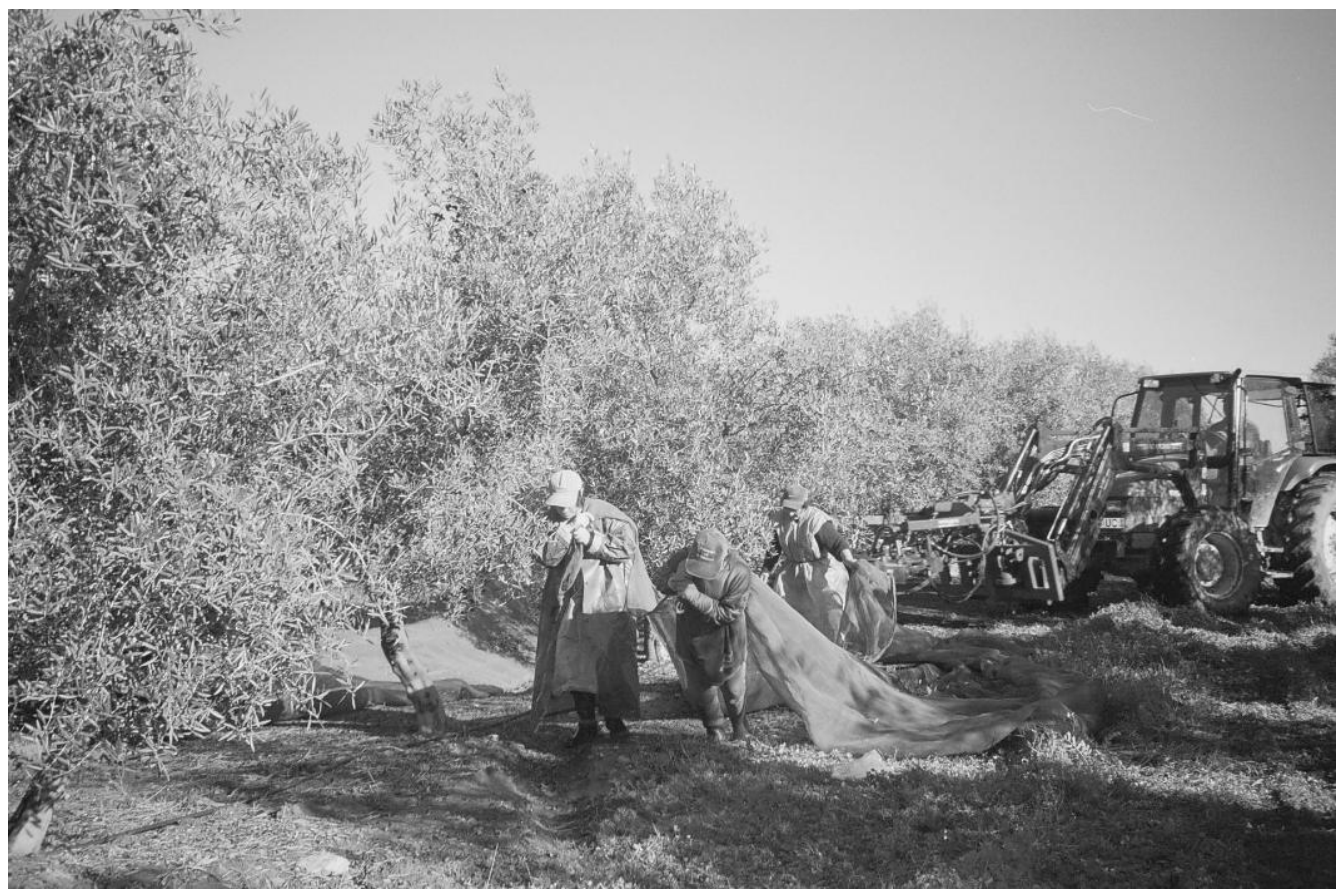

Fig.2. System 1: usual farmer harvesting system. 


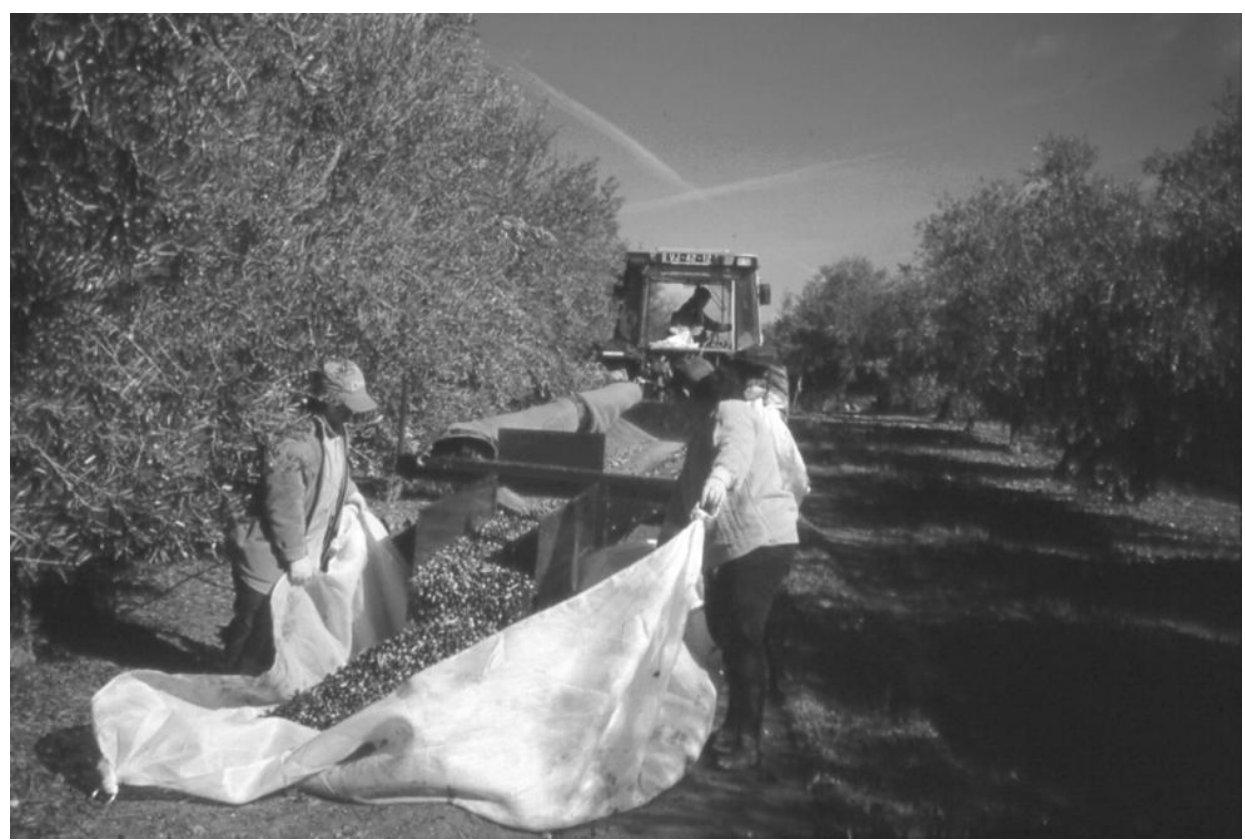

Fig.3. Rolling canvas prototype doing the discharge operation.

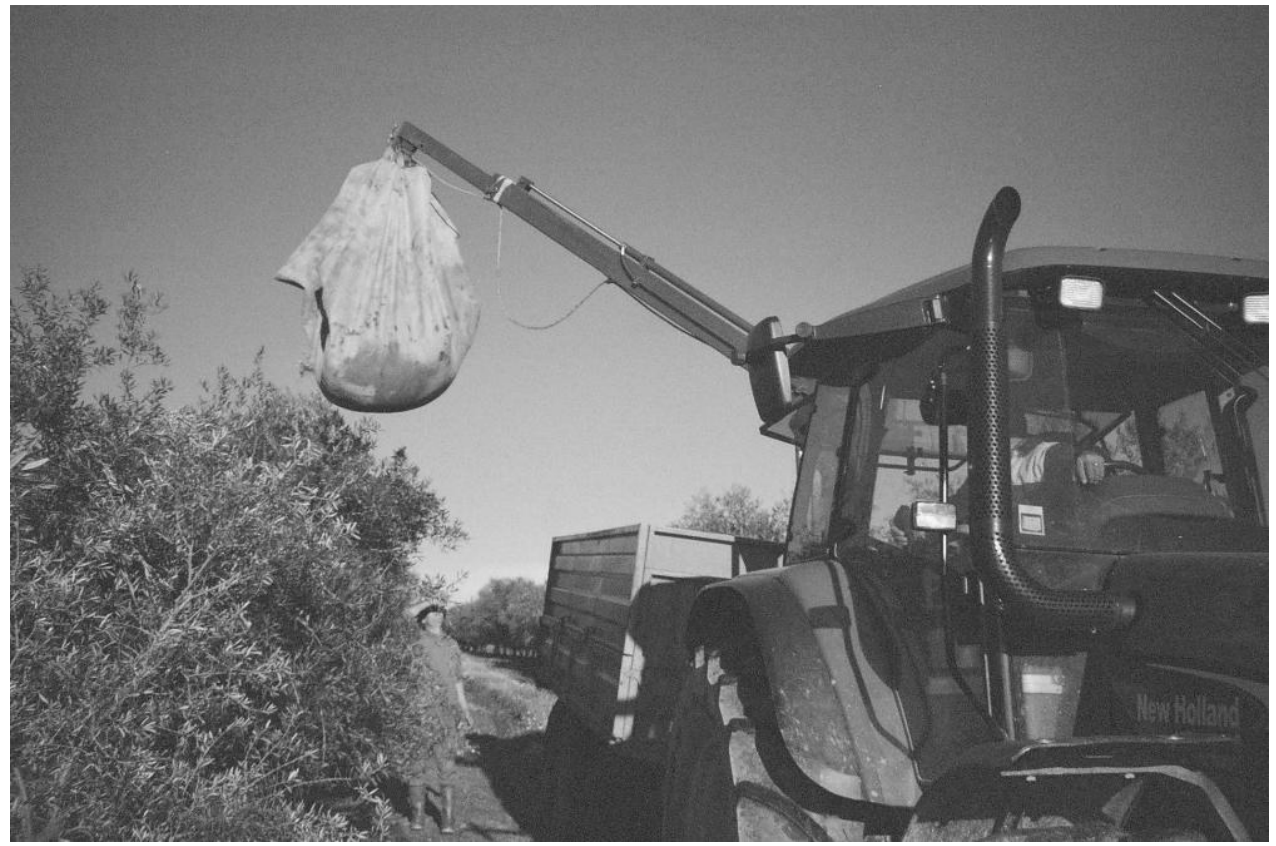

Fig.4. Rear mounted hydraulic crane, loading olives. 